\title{
TAMADUN ISLAM DALAM PERKEMBANGAN ERA GLOBALISASI
}

\author{
Hj. Baharudin \& Siti Aishah Yahya \\ E-mail : dr_baharudin@yahoo.com \\ Kolej Universiti Islam Melaka \\ KM 45, Kuala Sungai Baru, 78200 Melaka
}

\begin{abstract}
Education of Islam civilization has a very great challenge especially for Muslims all over the world. Education has been a priority in developed countries, such as United States, Japan, Australia, Russia, United Kingdom, and China, and Islamic countries, such as United Arab Emirate (UAE), Saudi Arabia, Bahrain, Quwait, Jordan, and so on. Proved that the countries belonging to the Muslim community itself are not to develop a real education and not in line with the progress of education, especially in western countries. Thus, it has been for centuries that the progress in terms of education entirely dominated by western countries. while all knowledge is derived from Islamic countries which has been revealed the holy Quran to the Prophet Rasulullah SAW.
\end{abstract}

Keywords: Islam civilization, development of globalisation era.

\section{PENDAHULUAN}

Beberapa bentuk persoalan terukir seperti, mengapakah negaranegara Islam di Asia Tenggara kemajuan pendidikan Tamadun Islam sangat lemah?. Contohnya di Malaysia, umat Islam yang terdiri daripada majoritinya Bangsa Melayu, memerlukan rujukan bantuan pendidikan dari negara-negara barat. Persoalannya, sejauh manakah bangsa Melayu untuk mengharapkan pendidikan dari Negara barat dan bagaimanakah untuk mengurangkan kepergantungan dari Negara barat serta apakah peranan Pertubuhan Persidangan Islam (OIC) dan kerajaan Malaysia untuk meningkatkan pendidikan terutamanya kepada bangsa Melayu yang beragama Islam ini. Bagaimana pula dengan negara-negara lain yang mempunyai ramai penduduk Islam dan peranan umat Islam memperkasakan ilmu pengetahuan untuk menjana bangsa sendiri.

Bagaimana kita mahu membangkitkan Tamadun Islam seiring dengan era globalisasi yang semakin mencabar akidah setiap umat Islam didunia ini, dan apakah langkah sewajarnya yang perlu diambil? Hanya umat Islam yang mendalami ilmu agama serta dibentengi oleh ketakwaan yang tinggi sahaja yang boleh melemahkan segala anasir-anasir yang mendatangkan kesesatan yang nyata ini. Mereka ini sentiasa menjaga ilmu mereka dengan takwa.

Ketakwaan yang perlu ada pada setiap umat Islam bagi membentengi diri mereka dari segala kekuatan negara barat untuk menghancurkan tamadun umat Islam yang dibina sejak awal berkurun dahulu. Ini adalah kerana terpadat pelbagai agenda Yahudi untuk menjatuhkan umat Islam 
khususnya dengan salah satu cara yang menjadi kekuatan mereka adalah dengan penjajahan pemikiran dan fahaman yang menyesatkan. Contohnya, kali pertama umat Islam terpengaruh dengan sekularisme. Tokoh yang terkenal dalam fahaman sekularisme ini adalah Harun Nasution dan Nurcholis Madjid. Kemudiannya muncul pula gelombang baru "Islam Liberal" yang diwakili oleh kelompok yang lebih muda yang diketuai oleh Ulil Abshar Abdalla yang membawa fahaman liberal ini. Kini dibawakan fahaman pluralisme yang hampir sama dengan fahaman liberal yang bertujuankan menyamaratakan semua agama. Ini dapat dibuktikan ketiga-tiga agenda ini telah disusun terlebih dahulu oleh pihak barat agar kekuatan umat Islam rosak, mundur dan seterusnya tamadun Islam akan jatuh sedikit demi sedikit.

\section{LATAR BELAKANG}

Tamadun secara umumnya adalah ditakrifkan sebagai pencapaian manusia dalam bidang kebendaan disamping tidak mengabaikan tentang aspek-aspek kerohanian yang menjadi panduan kearah kesempurnaan kehidupan didunia dan akhirat. Menurut Ibn Khaldun iaitu salah seorang tokoh terkenal dalam Islam, tamadun bermaksud umran. Umran bermakna asal tanah, tempat yang didiami manusia, mempunyai persediaan yang cukup untuk manusia dan keperluannya, pencapaian manusia yang melebihi keperluan asasi kehidupan dapat membuka jalan kearah pemikiran dan penghasilan daya cipta yang lebih halus dan mempuyai nilai-nilai seni. Manakala maksud tamadun dari salah seorang tokoh barat pula iaitu Beatty \& Johnson, kehidupan kota dan tulisan adalah asas utama kelahiran sesuatu tamadun (PPG, 2010).

Berdasarkan kepada penakrifan tamadun itu tadi, telah terjawab persoalan kecenderungan untuk mengkaji isu ini adalah kerana dilihat pada masa kini, kesedaran umat Islam terhadap kepentingan keseimbangan tamadun Islam dengan era globalisasi sangat membimbangkan yang akhirnya akan menjatuhkan umat Islam diseluruh dunia jika kita tidak kuat dari segi akidah islamiah yang diwarisi sejak zaman berzaman. Tanpa kita sedari, sedikit demi sedikit, tamadun Islam yang telah dikembangkan oleh khalifah-khalifah pada zaman khulafa' ar-Rasyidin diambil alih pucuk pimpinannya oleh masyarakat Barat. Contoh yang sangat mudah adalah umat Islam majoritinya lebih bangga menguasai bahasa Inggeris daripada bahasa Arab sedangkan Al-Quran diturunkan kepada kita dalam bahasa Arab. Kenapa perkara ini terjadi kerana bahasa Inggeris telah menjadi sumber rujukan sebagai bahasa ilmu.

Ini dapat dibuktikan lagi, kaum Orientalis yang terdiri daripada pengkaji-pengkaji Barat terhadap Islam yang mempunyai ideologi untuk mencari berbagai cara untuk menjatuhkan umat Islam seterusnya Negara Islam. Bermula dengan perang salib untuk mencari titik-titik kelemahan umat 
Islam dengan mudahnya dapat ditaklukan tanpa menggunakan senjata peperangan yang canggih. Kajian Orientalis ini terus tumbuh dan berkembang dari zaman ke zaman dengan kerjasama yang kuat dengan kolonisme Barat yang menjajah dunia Islam sehingga pertengahan abad ke20 masehi.

Tanpa kita sedari juga, semenjak era kemerdekaan Negara-negara Islam dari penjajahan Barat, fungi missionaris mereka tetap berjalan. Contohnya, dari segi penulisan yang mereka hasilkan penuh dengan kesesatan, memutarbelitkan dan menyelewengkan. Ini semua bertujuan untuk menjadikan kaum muslimin menjadi ragu kepada agama Islam dan apabila keadaan ini berlaku, maka kaum missionaris ini akan masuk dengan menjajah pemikiran dan menaburkan janji-janji kepada mereka, agar mereka terjebak dengan janji palsu ini seterusnya meninggalkan agama Islam atau paling tidak kehilangan rasa percaya terhadap agamanya sebagai satusatunya agama yang benar. Oleh itu, kaum muslimin yang telah terdidik dan telah berjaya dipengaruhi oleh pemikiran orientalis telah menyebarkan pemikiran-pemikiran yang mendatangkan keraguan terhadap Islam kepada masyarakat Islam yang lain melalui penulisan, media massa dan ceramahceramah mereka (Henry Nurdi, 2010).

\section{PERANAN PENDIDIKAN ISLAM DALAM PEMBENTUKAN ROHANI MANUSIA}

Perkembangan pendidikan barat tidak seiring dengan perkembangan pendidikan Islam yang mengkaji secara halus dalam perkembangan rohani dan jasmani seorang khalifah dimuka bumi ini. Jika kesedaran dalam umat Islam timbul dari segi rohani dan jasmani, maka mereka tidak akan menjadikan alasan kemunduran dari segi insfrakstrutur dan prasarana negara untuk menjadikan seseorang yang beragama Islam itu maju dari segi segala sudut ilmu pengetahuan.

Kesadaran ini sepatutnya berlaku dinegara-negara Asia yang terdiri daripada negara Islam terlebih dahulu dan seterusnya akan menjadi kekuatan untuk membangkitkan pendidikan Islam di seantero dunia. Ini dapat dibuktikan, cabaran-cabaran yang dihadapi oleh umat Islam di Afghanistan yang kurang dari segi pendidikan teknologi, maka negara mereka akan bergantung sepenuhnya kepada negara-negara barat untuk memenuhi kemajuan teknologi yang seiring dengan negara-negara lain.

Bagaimana pula negara Palestin dengan mudahnya dirampas oleh Israel melalui serangan-serangan yang dilancarkan disebabkan kekurangan ilmuilmu peperangan dan tiada kemudahan-kemudahan peralatan perang untuk melindungi negara mereka sendiri. Maka, disini apabila dilihat betapa pentingnya pendidikan kepada tamadun Islam pada masa sekarang yang berakar umbikan pendidikan rohani. 
Konsep pendidikan rohani mempunyai kaitan dengan pengertian qalbu, nafsu, akal dan roh. Tokoh yang terkenal dalam pendidikan rohani ini adalah Imam Al-Ghazali yang telah banyak memberi pendapat dalam pengertian istilah-istilah dalam bukunya "Ihya Ulumuddin"(Prof.Madya Dr.Khaidzir et.all, 2009).Imam Al-Ghazali telah membahaskan satu-persatu setiap istilah-istilah berikut:

\section{Qalbu (Hati)}

Adalah komponen yang membolehkan seorang insan itu melakukan analisis, sintesis dan memberikan makna kepada apa yang dicerap oleh seseorang. Allah swt berfirman:

"Dan sesungguhnya Kami jadikan untuk isi neraka Jahanam kebanyakan dari Jin dan Manusia, mereka mempunyai Qulb, tetapi tidak dipergunakannya untuk memahami (ayat-ayat Allah swt) dan mereka mempunyai mata (tetapi) tidak dipergunakannya untuk melihat (tanda kekuasaan Allah swt), dan mereka mempunyai telinga (tetapi) tidak dipergunakannya untuk mendengar (ayat-ayat Allah). Mereka itu sebagai binatang ternak, bahkan mereka lebih sesat lagi. Mereka itulah orang-orang yang lalai" (Al-A'raf 7:179).

\section{Nafsu}

Satu lagi komponen yang membina manusia adalah an-Nafs. Nafs adalah potensi diri yang membolehkan diri itu 'merasa' suka, sedih, seronok, bangga, puas, bahagia, derita dan sebagainya yang dijelmakan oleh dorongan dalam diri.Nafs adalah komponen yang ada pada diri insan yang memungkinkan diri tersebut bekerja keras untuk membenci kekufuran dan mencintai keimanan, membenci untuk melakukan perkara yang terkeji dan suka untuk melakukan perkara terpuji.

Firman Allah swt ;

"Mereka merasa telah memberi nikmat kepada mu dengan keislaman mereka. Katakanlah "Janganlah kamu merasa telah memberi nikmat kepada ku dengan keislamanmu, sebenarnya Allah swt, Dialah yang melimpahkan nikmat kepada mu dengan menunjukkan kamu kepada keimanan jika kamu adalah orang-orang yang benar" (Al-Hujurat 49:17).

\section{Akal}

Adalah satu komponen yang terdapat pada diri insan yang membolehkan seseorang itu berfikir. Dari segi fizikalnya, ia merupakan otak. Struktur biologinya sama diantara manusia dengan haiwan tetapi kuantitinya sahaja berbeza. Dari segi kerohanian pula, akal merupakan satu keupayaan untuk menggarap ilmu pengetahuan tentang hakikat segala hal.

Imam Al-Ghazali melihat akal sebagai salah satu entiti kerohanian yang memberikan kemampuan kepada manusia untuk berfikir dan membuat penaklukan bagi mengetahui segala hakikat tentang sesuatu. Akal juga sebagai tenaga untuk berfikir tentyang baik buruknya sesuatu perkara dan 
merasakan segala perubahan keadaan sehingga dapat mengambil manfaat darinya. Akal mampu membentuk keperibadian manusia dan merupakan hakikat kepada jiwa yang mempunyai ciri-ciri kemalaikatan.

\section{Roh}

Adalah komponen yang terdapat dalam diri seseorang tetapi ciri dan sifat fizikalnya tidak mungkin dapat difahami oleh manusia. Namun apa yang jelasnya Allah swt menyebut tentang manusia itu mempunyai komponen roh sebagaimana firmanNya ;

"Kemudian Dia menyempurnakan dan meniupkan kedalam (tubuh)nya dan roh (ciptaan) Nya...." (As-Sajadah 49:9).

Maka, terdapat empat perkara yang berkait dengan pendidika kerohanian ini yang perlu didik oleh setiap yang beragama Islam iaitu qalbu, akal, roh dan nafsu. Roh merupakan sesuatu yang sangat mulai dalam diri manusia yang merupakan tiupan dari pencipta manusia iaitu Allah swt. Manusia perlu memperolehi pendidikan rohani bagi memudahkan jalan menuju marifatullah dan membiasakan serta melatihnya untuk melakukan ibadah kepada Allah.

Oleh itu, roh perlu dididik dengan Pendidikan Islam agar manusia menjadi baik. Apabila manusia menjadi baik, maka seluruh masyarakatnya juga menjadi baik. Menurut Prof. Dr. Ali Abdul Halim Mahmud (2007), antara perkara yang perlu dititikberatkan dalam pendidikan rohani iaitu tiga perkara : Agar roh memiliki zikir dan sistem peraturanAgar roh dilatih, diajar dan diolah untuk menguatkan hubungannya dengan AllahAgar roh tetap berpegang teguh pada ciri-ciri khas setiap mukmin dalam diam, bercakap, bekerja ataupun tidak.

Maka, jika dalam diri setiap umat Islam mengetahui dan mengaplikasikan pendidikan rohani ini dalam diri, maka seluruh umat Islam terbela dan negara-negara Islam tidak lagi ditindas oleh penjajahan barat dengan sewenangnya.

\section{CABARAN DALAM ERA GLOBALISASI}

Sebelum melihat kepada cabaran-cabaran yang berlaku pada tamadun Islam pada masa kini, kita perlu melihat dengan persoalan mengapakah Negara-negara Islam masih lagi berkerjasama dengan barat bagi menghancurkan saudara Islam mereka sendiri?. Ini dapat dibuktikan dengan adanya beberapa negara, contohnya Negara Saudi Arabia. Terdapat banyak pengkalan militant yang digunakan oleh Amerika Syarikat seperti di Dammam, Jeddah, Riyadh, Tabuk, Thaif dan Jubail adalah nama-nama daerah yang digunakan oleh militant-militan untuk pesawat tempur Amerika. Terdapat 6500 pasukan Amerika bersiap siaga di markas-markas tersebut dengan berbekalkan 150 American Fighter, 6 jet tempur dan 300 pasukan Inggeris. 
Manakala di Turki pula, walaupun mereka menolak penyerangan Amerika terhadap Iraq, tetapi Amerika telah menggunakan Bandar International Turki, Incirlik Airport sebagai pengkalan udara mereka. Bukan setakat itu sahaja, Diyarbakir Airport dan Erchac dijadikan pula pengkalan udara mereka dengan memiliki 5400 pasukan tempur, 150 jet tempur yang terdiri dari F-15, F-16 dan pesawat pembom EA-6b Prowler serta 39 Air Expeditionary yang dirim telah siap siaga ke Iraq.

Menurut data yang diambil pada tahun 2010 ini juga, Negara Kuwait tidak berkecuali membantu Amerika melalui Ahmaed Al-Jabbar, Ali Al-Saleem dan Kuwait International Airport adalah tiga tempat yang dijadikan pengkalan udara oleh Amerika Syarikat di negeri ini. Amerika juga masih mempunyai tujuh pengkalan udara militant darat yang tersebar dipenjuru Kuwait. Terdapat 20,000 pasukan tempur Amerika, 80 jet tempur terasuk F-15 dan F-16, 176 kenderaan tempur jenis Bradley, 75 helikopter dan banyak lagi. Selain itu, pasukan penyelamat, mariner, tim amunisi dan bantuan udara adalah jenis pasukan yang disiapkan di Kuwait.

Contoh sebuah negara lagi yang menyokong Amerika dalam menyerang negara Islam adalah Bahrain telah dibangunkan pengkalan udara oleh militan seperti di Manama, Minam Salman dan Shaikh Isa Airport serta beberapa daerah lagi. Terdapat 6400 pasukan tentera telah bersiap sedia di sini. Bahrain juga menjadi salah satu pusat kendali dalam Perang Teluk II ini. Pejabat lima tingkat telah didirikan sebagai Pusat Komandor dan tentera yang mahir dari segala kemahiran berperang telah berada di Bahrain (Herry Nurdy, 2010).

Oleh itu, apa yang telah kita fikirkan setelah melihat kepada fakta diatas?. Oleh itu, kita telah menyedari bahawa terdapat cabaran yang sangat besar dalam era globalisasi sekarang terhadap umat Islam di dunia. Cabaran yang pertama adalah dari segi kebergantungan peralatan-peralatan elektronik terutamanya komputer, telefon bimbit, dan 'website' yang keseluruhannya memberi kebaikan kepada umat Islam tetapi penyalahgunaan oleh umat Islam yang menyebabkan umat Islam sendiri yang hancur dan mundur terutama kemunduran dari segi akidah kepada agama kita sendiri. Kebergantungan ini juga memberi kesan kepada perkembangan ekonomi terutamanya barangan eksport sesebuah negara itu sendiri menjadi lemah.

Selain itu juga, cabaran Negara-negara Islam untuk menyamaratakan barang-barangan import dan eksport sangat sukar terutamanya dari aspek pendidikan teknologi. Ini kerana, Negara-negara barat teramat maju dalam pendidikan teknologi dan seterusnya menjadikan Negara-negara barat memegang ekonomi dunia seperti Amerika Syarikat. Masyarakat Islam juga seolah-olah sudah ditanam bahawa hanya barangan Negara barat sahaja yang mempunyai kualiti. 
Disamping itu juga, cabaran yang dihadapi oleh umat Islam sekarang adalah dari segi pendidikan moral. Contonhya, masalah sosial sangat berleluasa dalam kalangan remaja-remaja Islam yang sangat mudah terpengaruh dengan gaya hidup barat. Terdapat juga masyarakat Islam yang menyalahgunakan barang-barang yang dilarang disesebuah Negara Islam seperti membantu pemberontak merampas peralatan-peralatan tentera, membunuh sesama Islam, menyimpan maklumat dan menggunakan medan sosial untuk memfitnah sesama sendiri.

Masalah budaya yang semakin dipinggirkan juga merupakan cabaran utama contohnya kepada bangsa melayu yang banyak terpengaruh dengan barat. Seperti, cara makan dan budaya kekeluargaan yang semakin renggang dan rapuh. Semua yang berlaku ini menunjukkan semua negaranegara Islam perlu bersatu untuk tidak memberikan kerjasama dan tidak memberi peluang kepada negara-negara yang menjadi musuh Islam mencari titik-titik kelemahan kepada umat Islam.

\section{CADANGAN}

Dalam era globalisasi yang sangat mencabar akidah dan keimanan umat Islam ini, kita perlu sentiasa persiapkan diri dengan membentengkan diri kita bagi menepis segala anasir-anasir barat yang bersiap sedia dan sentiasa memusuhi umat Islam. Antara cadangan-cadangan yang perlu diberi perhatian oleh umat Islam khususnya adalah:

\section{Membentuk akidah manusia yang benar}

Akidah merupaka perkara yang paling utama dalam mengajarkan manusia untuk mengenali dan mendekati Allah swt. Pembentukan akidah manusia yang sebenar meliputi keyakinannya terhadap Allah swt, keyakinannya terhadap para Malaikat, Kitab dan para Rasul, keyakinan terhadap hari akhirat, keyakinan terhadap qadak dan qadar Allah. Semua keyakinan yang lurus terhadap semua perkara ini akan memberikan keyakinan kepada manusia, kehidupan yang mulia yang diredhai oleh Allah swt.

\section{Mengajarkan ibadah yang benar}

Pengajaran dalam ibadah ini harus berasaskan daripada nas-nas yang terdapat dalam Al-Quran dan As-Sunnah. Ini kerana, tidak sempurna jika hanya belajar tetapi tidak dapat mengamalkan iman, Islam, keadilan, kebaikan dan amar makruf nahi mungkar secara teori sahaja.

\section{Menyebarkan semangat saling mengenali antara manusia}

Pendidikan Islam bertujuan untuk tolong-menolong antara manusia kerana sifat ini merupakan salah satu fenomena hubungan social, dan 
merupakan ungkapan bersama antara dua orang atau lebih dalam mewujudkan sifat tersebut.

\section{Bekerja untuk memakmurkan bumi}

Menjadi kewajipan manusia mempersiapkan manusia yang lain melalui pendidikan untuk menundukkan kemampuan alam semesta yang mengelilinginya yang akan membawa kebaikan di dunia dan di akhirat. Setiap ilmu pengetahuan yang berkesan pada tenaga manusia untuk memakmurkan bumi yang ditundukkan oleh Allah swt untuk diri manusia adalah termasuk ilmu dan seni yang dibawa oleh syariat Allah swt.

\section{Mengajar manusia berdisiplin}

Manusia yang berdisiplin mengetahui kewajipannya dan menunaikan kewajipan tersebut. Kewajipan yang dimaksudkan adalah, mengetahui kewajipan kepada Allah swt yang termaktub dalam Al-Quran dan Hadith. Berdisiplin dengan system Allah swt dalam amar makruf nahi munkar mempunyai kebaikan bagi keluarga, masyarakat dan umat Islam secara keseluruhannya. Apabila manusia telah berdisiplin, automatiknya mereka akan meninggalkan semua perkara-perkara yang negatif dan sia-sia.

\section{Membentuk manusia yang berdakwah menuju ke jalan Allah S.W.T}

Tujuan pendidikan Islam adalah membentuk manusia berdakwah menuju kejalan Allah swt dan memberikan tanggungjawab untuk keperluan tersebut dengan segala apa yang diperlukan. Seseorang yang ingin berdakwah, mereka memerlukan pengetahuan umum yang baik, pengetahuan Islam yang khas, pengetahuan mengenai pengertian dakwah kepada Allah swt, pengetahuan tentang da'l dan sebagainya.

\section{KESIMPULAN}

Kesimpulannya, manusia yang bertamadun merupakan manusia yang telah mencapai kemajuan dalam bidang kebendaan disamping tidak mengabaikan tentang aspek-aspek kerohanian yang menjadi panduan kearah kesempurnaan kehidupan didunia dan akhirat.

Oleh itu, tidak diragukan lagi bahawa pendidikan Islam kepada rohani memberikan kemampuan kepada umat Islam untuk hidup secara Islami yang benar dan jauh dari berlebihan dan kemunduran. Kehidupan Islami mendapati bahawa dalam roh atau jiwa adalah tiupan daripada Allah swt yang disampaikan kepada manusia disaat penciptaan Adam as. Roh juga akan menjadi bersih melalui taat dan akan menjadi kotor melalui maksiat. Ini dapat dibuktikan dalam firman Allah swt :

"Sesungguhnya berjayalah orang yang menjadikan dirinya yang sedia bersih- bertambah bersih (dengan iman dan amal kebajikan). Dan 
sesungguhnya rugilah orang yang menjadikan dirinya yang sedia bersih itu susut dan terbenam kebersihannya (dengan sebab kekotoran maksiat)"(AlSyams : 9-10).

Disamping itu juga, pemantapan akidah juga merupakan perkara yang sangat penting dalam menguatkan pemikiran umat Islam supaya dengan tidak mudahnya dijajah oleh barat. Akidah merupakan sesuatu yang dipercayai hati manusia secara tetap dan mantap. Apabila akidah kuat, jika perkara yang dating dan dipercayai itu berupa kebenaran ataupun kebatilan, umat Islam akan sentiasa dapat melihat kebenaran yang nyata.

Akidah dalam Islam juga adalah iman. Ini dapat dibuktikan dengan Hadis daripada Rasulullah saw tentang iman dan akidah adalah "... Beriman kepada Allah swt, para malaikatNya, semua KitabNya, para RasulNya, Hari Kiamat, dan beriman kepada qadar baik mahupun buruk..." (HR Muslim).

\section{DAFTAR PUSTAKA}

\section{Al-Quranul Karim}

Yusuf Al-Qardhawi. 2003. Menuju Kefahaman Islam yang Kaffah. Insan Cemerlang. Jakarta, Indonesia.

Henry Nurdi, 2010. Konspirasi Intelektual Yahudi (Belajar Islam dari Yahudi). Cakra Lintas Media. Jakarta, Indonesia.

Ali Abdul Halim Mahmud. 2007. Mencerdaskan Rohani (Siri Motivasi Membentuk Peribadi Mukmin Sejati Berpandukan Kepada Al-Quran dan Sunnah Nabi saw). Perniagaan Jahabersa. Johor.

Khaidzir Hj. Ismail et.all. 2009. Psikologi Islam, Falsafah, Teori dan Aplikasi. Institut Islam Hadhari, Universiti Kebangsaan Malaysia. Bangi. Selangor.

Samihah Mahmud Gharib. 2006. Membekali Anak dengan Akidah. Pustaka Magfirah. Jilid Pertama. Jakarta, Indonesia

Tamadun Islam \& Tamadun Dunia. 2010. Nota Kuliah (WAJ 3101). Program Pensiswazahan Guru. 